\title{
Investigation of the Questions in 8th Grade Mathematics Textbook in terms of Mathematical Literacy
}

\author{
Kamuran Tarim $^{1}$ (D), Hakan Tarku ${ }^{1 \star}$ (D) \\ ${ }^{1}$ Cukurova University, TURKEY \\ *Corresponding Author: hakantarku@gmail.com
}

Citation: Tarim, K., \& Tarku, H. (2022). Investigation of the Questions in 8th Grade Mathematics Textbook in terms of Mathematical Literacy. International Electronic Journal of Mathematics Education, 17(2), em0682. https://doi.org/10.29333/iejme/11819

\begin{abstract}
ARTICLE INFO
Received: 1 Jan. 2022

Accepted: 16 Feb. 2022

ABSTRACT

The aim of this study is to determine the distribution of the questions in an 8th grade mathematics textbook in terms of the categories (mathematical content, mathematical literacy contexts, mathematical processes, PISA mathematics proficiency scale levels, and item types) within the PISA mathematics literacy framework. Investigation of the questions in the book reveals that the content category with the highest number of questions is "quantity" and the content category with the least number of questions is "uncertainty and data." It is seen that the context with the most questions is "scientific context" and the context with the least number of questions is "societal context." It is seen that the most preferred process category is "employing mathematical concepts, facts, procedures and reasoning", while the least preferred process category is "Formulating situations mathematically." According to PISA mathematics proficiency levels, it is seen that the fifth and sixth level questions are not included, and the fourth level questions are very scarce. It was determined that the second level questions were the most preferred type in the book. This situation is in parallel with the mathematics proficiency level (level 2) of our country stated in the PISA 2018 exam evaluation report. When the distribution of the questions by the PISA mathematics scale levels on the basis of item types is examined, it is seen that there are a large number of open-ended questions. The distribution of the PISA mathematics proficiency scale high-level questions, which are rare in the book, shows that the most preferred item type in asking these questions is the "open-ended" item type. In the writing of mathematics books, it is recommended to pay attention to the balanced distribution of questions on the basis of mathematical literacy contexts, mathematical processes and content categories, and to include more high-level questions.
\end{abstract}

Keywords: OECD, PISA, mathematical literacy, contexts, mathematical processes, content category, question types, mathematics proficiency scale, mathematics proficiency levels, middle school 8th grade, textbook

\section{INTRODUCTION}

What distinguishes human beings from others is the ability to think, to make sense of events and to adapt the conditions to themselves (their needs). One of the most important tools to develop thinking capacity is mathematics. Mathematics education not only teaches numbers and formulas, but also helps to tackle the ever-changing living conditions. It provides support in gaining thinking skills such as reasoning, making connections between events, making predictions, and solving problems (Umay, 2003). With the technological developments, the understanding of classical mathematics has changed and the concept of mathematical literacy, which is based on modeling and application, has emerged. An individual who can employ mathematics to meet a need that arises in daily life is considered to be mathematics literate (Canbazoglu, 2019; Canbazoglu \& Tarim, 2021; Canbazoglu et al., 2019). So much so that this skill, which appears as the ability to use mathematics in life, is measured as a focal point in international exams (PISA, TIMSS, etc.) (Uysal, 2009). One of these exams, the PISA exam, is administered by the Organization for Economic CoOperation and Development (OECD) and many countries participate voluntarily.

The definition of mathematical literacy made in PISA 2012 was used in the same way in PISA 2015 and 2018 (MEB, 2019). According to the definition made, mathematical literacy is the capacity of individuals to formulate, use and interpret mathematics. This concept includes mathematical reasoning and using mathematical concepts, methods, facts and tools to describe, explain and predict variables. It helps people to recognize the role of mathematics in the world and to make the right decisions for the situations encountered (OECD, 2019a). In order to increase the capacity to use mathematics in life, every dimension of educational environments should be arranged accordingly. One of these dimensions is the textbooks offered to students.

The implementation of the curricula in schools is ensured by the textbooks prepared based on the curriculum. An important part of learning environments is textbooks (Cakir, 2009). The standards of the textbooks are determined by the Board of Education and Discipline and are written in accordance with these standards (Altun et al., 2004). Textbooks guide the teacher on to which 
extent to teach each subject in the classroom and how to determine a strategy (Tyson \& Woodward, 1989). Textbooks, as a source of information, guide students according to the objectives of the course. The level of quality of a textbook is proportional to its usefulness to students. Therefore, textbooks have an important place in education (Unsal \& Gunes, 2002). Since the textbooks are an indispensable resource for teaching environments, it is thought that it is important to examine and evaluate them. With investigation of textbooks studies, textbooks can be made more desirable and more effective.

Our country ranked 42nd among 79 countries participating in PISA 2018, and 33rd among 37 OECD countries, with 454 points in the field of mathematics (MEB, 2019). When evaluated in terms of mathematics proficiency, which has six levels, our country is at the second level. The reasons for our ranking so far behind should be examined. While examining these reasons, it was thought that it is important to determine how much the content presented to students in mathematics textbooks, which is one of the main resources, can support them in becoming the above-mentioned mathematics literate, in increasing student success. In this respect, it is important to examine and classify the questions in the textbooks with respect to the PISA mathematics proficiency levels, to compare the positive and negative situations, to identify the deficiencies and to make various recommendations in eliminating the deficiencies in the textbooks.

When the studies on textbooks are examined, many studies are found. However, only three studies were found in which mathematics textbooks were examined in the context of the PISA framework. The first of them is Seis's (2011) study, which examines probability and statistics subjects with regard to PISA 2003 uncertainty proficiency scale levels in a total of 9 textbooks by three different publishers at each grade level for the 6-8 grade textbooks used in Turkey using the document analysis method. This study concluded that, no task belonging to the sixth level, which is the highest level, was found in the questions on probability and statistics in the mathematics textbooks. The tasks of the fifth level are almost non-existent. In another study, Iskenderoglu and Baki (2011) analyzed and classified the questions in one of the 8th grade textbooks according to the PISA mathematics proficiency scale. As a result of the research, it was seen that the 8th grade textbook did not include questions at all levels. While it was seen that there were questions at the 1st, 2nd, 3rd, and 4th levels in the book, there were no questions at the 5th and 6th levels. The last study is by Yildirim (2019), which examines 5-8th grade mathematics textbooks. In this study, Yildirim (2019) aimed to determine how much the textbooks cover the levels of the PISA change and relations proficiency scale (there are six levels), and how it varies with respect to learning areas and grade levels. In addition, in his study, he examined how much the algebra learning field in the textbooks reflected the change and relations proficiency scale levels. According to the results obtained, no tasks belonging to the $4 \mathrm{th}, 5^{\text {th }}$, and 6 th levels were found in the questions in the mathematics textbooks.

When the studies mentioned above are examined, it is seen that the textbooks are mostly examined with regard to the proficiency scale levels. However, no study has been found in which the levels of the questions in a textbook are classified with regard to the PISA mathematics proficiency scale, together with classification by their mathematical literacy contexts, mathematical processes, content categories, and question types, and their distribution is revealed. Examining the questions in the textbook in terms of all these categories is important in terms of evaluating the textbook as a whole, reflecting its content better and revealing its status.

In the next section, it is explained in which dimensions the 8th grade mathematics books are examined in the framework of PISA mathematics literacy.

\section{MATHEMATICAL LITERACY ASSESSMENT CATEGORIES IN PISA FRAMEWORK}

A number of content categories have been identified for the PISA 2018 framework. These categories are change and relationships, space and shape, quantity, uncertainty, and data. Change and relationships mean that a mathematical change is associated with appropriate equations and functions and modeled. Equations, inequalities, tabular and graphical representations, functions, and algebra have an important place in describing, interpreting, and modeling changes. Representations of data and correlations described using numerical values are often used to reveal and interpret changes and relationships. Space and shape include various phenomena encountered in many parts of life, e.g., motifs, location of an object, navigation used to find addresses, representation of objects, geometric shapes, space, visual information analysis, dynamic geometry software, and many similar situations and events are included in this content category. PISA makes the assumption that a set of core concepts and skills are important to mathematical literacy in terms of space and shape. Mathematical literacy in the field of space and shape includes a series of activities such as creating representations, interpreting the appearance of threedimensional objects from various angles, creating maps and understanding these maps, and transforming shapes.

Another category is the quantity category. The quantity category covers the quantification of the attributes of objects, states, and entities in the environment. It involves understanding different representations of quantities and evaluating associated interpretations. Quantification requires an understanding of measurements, sizes, numbers, units, indicators, numerical trends. Aspects of quantitative reasoning, such as perceiving numbers and their multiple representation, estimating results, and evaluating results, are at the core of mathematical literacy with regard to quantity. Another category is uncertainty and data. In this category, situations of uncertainty are often encountered in many parts of daily life, in science and technology. In order to get rid of these uncertainties, probability statistics theory and data identification techniques have been developed. There are uncertainties in weather and scientific forecasts and survey results. Interpreting and presenting data is an important aspect of uncertainty and data category. The contents of the questions in PISA 2015 and PISA 2018 were distributed into the four main categories described above. A balanced distribution of content categories is important for raising individuals who think constructively and reflectively. 
Table 1. Desired distributions of mathematics items by content, context, and process in PISA 2018 categories

\begin{tabular}{|c|c|}
\hline Category & Percentage (\%) \\
\hline \multicolumn{2}{|l|}{ Content category } \\
\hline Change and relationships & 25 \\
\hline Space and shape & 25 \\
\hline Quantity & 25 \\
\hline Uncertainty and data & 25 \\
\hline Total & 100 \\
\hline \multicolumn{2}{|l|}{ Context category } \\
\hline Personal & 25 \\
\hline Occupational & 25 \\
\hline Societal & 25 \\
\hline Scientific & 25 \\
\hline Total & 100 \\
\hline \multicolumn{2}{|l|}{ Process category } \\
\hline Formulating situations mathematically & 25 \\
\hline Employing mathematical concepts, facts, procedures and reasoning & 50 \\
\hline Interpreting, applying and evaluating mathematical outcomes & 25 \\
\hline Total & 100 \\
\hline
\end{tabular}

The context in which the mathematical problem arises is important for the selection of solution strategies and appropriate representations of the problem (OECD, 2019a). For the purposes of the mathematics framework, contexts were defined in four different categories (personal, professional, societal, and scientific) in the PISA 2018 assessment. Questions classified under the category of personal context focus on the activities of the individual, family members, or group of friends. Examples of these types of contexts are personal planning, transportation and health, food preparation, shopping, games, sports, travel, and similar contexts. The area where the problems classified in the occupational context category are concentrated is the business world. Occupational contexts can relate to any line of business and level, but should be understandable to 15-year-old students. Questions classified under the category of societal context are related to the individual's community. Societal context may cover (but is not limited to); electoral systems, public transport, government, national policies, demography, economics, etc. In the category of societal context, the focus of questions is society. Finally, the problems classified in the scientific category are related to the application of mathematics to daily life, science and technology. Scientific context may include (but is not limited to) fields such as weather, climate science, ecology, the medical industry, space science, genetics, and the nature of the mathematical world. All relevant elements in the world of mathematics are in scientific context. In the PISA 2015 and 2018 mathematics assessment, four different context categories were determined. It is important that these contexts are evenly distributed and that no single context type is dominant (OECD, 2019a). Because in this way, items containing different situations that they are likely to encounter in their lives are presented to the students in a balanced way. Thus, individuals are prepared for the problem situations they may encounter in daily life.

In PISA 2018, questions in mathematics assessment were assigned to one of three mathematical processes (OECD, 2019a):

1. Formulating situations mathematically,

2. Employing mathematical concepts, facts, procedures, and reasoning, and

3. Interpreting, applying, and evaluating mathematical outcomes.

In the process of formulating situations mathematically, the problem in the real life environment is transformed into the field of mathematics. In the process of Employing mathematical concepts, facts, procedures, and reasoning, individuals perform the necessary mathematical processes to obtain results and find a mathematical result (solution). In the process of Interpreting, applying, and evaluating mathematical outcomes, it is determined whether the mathematical solutions and results are acceptable and whether they are meaningful. The desired distributions of the content, context, and process categories are given in Table 1.

The questions in PISA 2018 are divided into six different mathematics proficiency categories. In Table 2, explanations of these categories and what individuals at this category level are able to do are given.

In light of all the reasons and theoretical explanations explained above, the aim of this research is to determine the distribution of the questions in an 8th grade textbook with regard to content category, mathematical literacy contexts, mathematical processes, the PISA mathematics proficiency scale levels, and item types.

\section{METHOD}

In this study, document review technique, one of the qualitative research data collection methods, was used to obtain data. Bowen (2009) defined document review as a systematic process used to review or evaluate printed or digital materials. The questions in the Ministry of National Education Middle School Mathematics 8 Textbook used as an 8th grade mathematics textbook in the 2019-2020 academic year in Adana province, were examined with regard to the mathematical literacy contexts, mathematical processes, item types of the questions, content category, and the Mathematics Proficiency Scale in PISA 2018.

The 8 th grade was chosen as the grade level because the students taking the PISA exam are 15 years old and the success of the students in this age group in the PISA exam is related to the knowledge they have acquired in previous years. 
Table 2. Brief description of six mathematics proficiency levels in PISA 2018

\section{Level What are the students at this level able to do?}

Students at this level are able to conceptualize, generalize, and use knowledge based on their research and modeling of complex problem situations, and use their knowledge in relatively non-standard contexts. They can link and flexibly translate between different sources of information and representations. Students at this level are capable of advanced mathematical thinking and reasoning. These students are able to apply this insight and understanding, while mastering symbolic and formal mathematical operations and relationships, to develop new approaches and strategies for attacking new situations. Students at this level can reflect on their actions and formulate and fully communicate findings, interpretations, arguments and their actions and reflections on their relevance to the original situation.

Students at this level can develop and work with models for complex situations and identify constraints and assumptions. They can select, compare and evaluate appropriate problem-solving strategies to deal with complex problems related to these models. Students at

5 this level can work strategically using broad, well-developed thinking and reasoning skills, appropriate connected representations, symbolic and formal characteristics, and insight into these situations. They begin to reflect on their work and are able to formulate and communicate their interpretations and reasoning.

Students at this level can work effectively with explicit models for complex concrete situations that may involve constraints or require making assumptions. They can choose and integrate different representations, including symbolic, directly linking them to aspects of real-world situations. Students at this level can use their limited skills and reason with insight in simple contexts. They can create and communicate explanations and arguments based on their interpretations, arguments, and actions.

At this level, students can follow clearly described procedures, including procedures that require sequential decisions. Their interpretations are robust enough to create a simple model or to select and apply simple problem-solving strategies. Students at this

3 level can use and interpret presentations directly from different sources of information and justifications. They often demonstrate an ability to handle percentages, fractions, and decimals and work with proportional relationships. Their solutions show that they are dealing with basic interpretation and reasoning.

At this level, students can interpret and recognize situations in contexts that require no more than direct inference. They can extract

2 relevant information from a single source and benefit from a single representative mode. Students at this level can use basic algorithms, formulas, procedures or rules to solve problems involving integers. They can make real interpretations of the results.

Students at this level can answer questions involving familiar contexts where all relevant information is available and questions are

1 clearly defined. In clear situations, they can identify information and perform routine procedures according to direct instructions. They can perform actions that are almost always obvious and immediately follow through from given stimuli.

Table 3. Units and subject headings in the book

\begin{tabular}{ll}
\hline Unit name & Unit subject heading \\
\hline Unit 1 & Factors and multiples-Exponents \\
\hline Unit 2 & Square root expressions-Data analysis \\
\hline Unit 3 & Probability of simple events-Algebraic expressions and identities \\
\hline Unit 4 & Linear equations-Inequalities \\
\hline Unit 5 & Traingles-Congruency similarity \\
\hline Unit 6 & Transformation geometry-Geometric bodies \\
\hline
\end{tabular}

Table 4. Frequency and percentage distribution of questions by units

\begin{tabular}{lcc}
\hline Unit name & Frequency (N) & Percentage (\%) \\
\hline Unit 1 & 147 & 15.3 \\
\hline Unit 2 & 177 & 18.5 \\
\hline Unit 3 & 172 & 18.0 \\
\hline Unit 4 & 159 & 16.6 \\
\hline Unit 5 & 130 & 13.6 \\
\hline Unit 6 & 173 & 18.1 \\
\hline Total & $\mathbf{9 5 8}$ & $\mathbf{1 0 0 . 0}$ \\
\hline
\end{tabular}

In this study, first of all, all the solved and unsolved questions in the 8th grade mathematics textbook were examined, and the possible solutions of the questions were found. Then, with these solutions, a tag was created for each question. In this tag the following attributes of each question were determined; which of the six different item types (fill in the blanks, matching, sample solution, multiple choice, true-false, and open-ended), which of the four different content categories (change and relationships, space and shape, quantity, uncertainty, and data), which of the four different mathematical literacy contexts (personal, professional, societal, and scientific), which of three different mathematical processes [(i) formulating situations and problems mathematically, (ii) using mathematical concepts, facts, and processes, and (iii) mathematical outputs interpretation, application, and evaluation] and which of the six different levels in the PISA 2018 proficiency scale it appertains to. Thus, classification of the questions was made. There are six units in this book under review. The names and subject headings of units are given in Table 3.

In the book, the questions are given under titles such as "Are we ready?", "Let's remember", "Let's learn together", "Let's research and think", "It's your turn", "Unit evaluation". In addition, on the cover of each unit, thought-provoking questions were included under the name of "Mind game". By examining 958 questions given under these headings, these questions were classified under, content category, contexts, item types, mathematical processes and PISA mathematical literacy proficiency scale. The distribution of the questions according to the units is given in Table 4. Table 4 shows a generally even distribution of the questions across the units. 
Table 5. Frequencies and percentage distributions of questions by content, context, process, and PISA mathematical literacy proficiency scale levels

\begin{tabular}{|c|c|c|}
\hline Category & Frequency (N) & Percentage (\%) \\
\hline \multicolumn{3}{|l|}{ Content category } \\
\hline Change and relationships & 122 & 12.7 \\
\hline Space and shape & 339 & 35.4 \\
\hline Quantity & 391 & 40.8 \\
\hline Uncertainty and data & 106 & 11.1 \\
\hline Total & 958 & 100.0 \\
\hline \multicolumn{3}{|l|}{ Context category } \\
\hline Personal & 90 & 9.4 \\
\hline Occupational & 82 & 8.6 \\
\hline Societal & 14 & 1.5 \\
\hline Scientific & 772 & 80.6 \\
\hline Total & 958 & 100.0 \\
\hline \multicolumn{3}{|l|}{ Mathematical process category } \\
\hline Formulating situations mathematically & 28 & 2.9 \\
\hline Employing mathematical concepts, facts, procedures, and reasoning & 767 & 80.1 \\
\hline Interpretation, application, and evaluation of mathematical results & 163 & 17.0 \\
\hline Total & 958 & 100.0 \\
\hline \multicolumn{3}{|l|}{ PISA mathematical literacy proficiency scale levels } \\
\hline First level & 188 & 19.6 \\
\hline Second level & 417 & 43.5 \\
\hline Third level & 341 & 35.6 \\
\hline Fourth level & 12 & 1.3 \\
\hline Fifth level & 0 & 0.0 \\
\hline Sixth level & 0 & 0.0 \\
\hline Total & 958 & 100.0 \\
\hline
\end{tabular}

In addition to the researchers, two experts who were graduate students in primary school mathematics education and trained in PISA and mathematical literacy, made the classification of the questions in the book. The researchers classified all the questions in the book, and $10 \%$ of these questions were chosen to represent all the questions in the book, and the experts were allowed to classify these questions. For mathematical content, mathematical literacy contexts, mathematical processes and item types classifications made by researchers and experts were in 100\% agreement and $94 \%$ for the PISA math proficiency scale levels. The classifications made by the experts and researchers were compared and the questions on which there was a consensus were taken as they were. The questions on which no consensus could be reached were reviewed together and classified according to a common decision. In this way, the classification of all questions according to the determined criteria was completed.

\section{RESULTS}

The following findings were obtained by investigating one of the Middle school 8th Grade Mathematics Textbooks distributed by the Ministry of National Education in the 2019-2020 academic year.

The distributions of the questions in the book by the content, mathematical literacy context, mathematical process, and the PISA mathematical literacy proficiency scale levels categories are given in Table 5.

Looking at Table 5, it is seen that the content category with the highest number of questions is "quantity" with $40.8 \%$ (391 questions), while the content category with the least number of questions is "uncertainty and data" with $11.1 \%$ (106 questions). Table 5 reveals that the context with the highest number of questions is "scientific context" with $80.6 \%$ ( 772 questions), while the context with the least number of questions is "societal context" with $1.5 \%$ (14 questions). Most of the scientific context questions, $91.4 \%$ (706 questions) consist of questions involving only mathematical operations, while a very small portion of them, $8.6 \%$ (66 questions) include the application of mathematics to the natural world, science and technology. Table 5 reveals that the most preferred process category is "Employing mathematical concepts, facts, procedures, and reasoning" with $80.1 \%$ ( 767 questions). The least preferred process category was "Formulating situations mathematically" with $2.9 \%$ (28 questions). An inspection of the data in Table 5 reveals that the questions are mostly at the second proficiency level with $43.5 \%$ (417 questions). It is noted that the questions at the fourth level are very few in the book with $1.3 \%$ (12 questions), and the questions at the fifth and sixth levels are not included in the book.

$19.6 \%$ (188 questions) of the questions in the book are at the first level according to the PISA mathematical literacy proficiency scale. Students at level one can answer questions involving familiar contexts they already know when all information is given clearly. In explicit situations, they can describe information according to direct instructions. A question at the first level of the PISA mathematical literacy proficiency scale on page 23 of the book examined is given in Figure 1 . There is no need to make any inferences to solve the problem in Figure 1. A previously known situation was explicitly asked. For this reason, it is seen that the problem is at the first level of the PISA mathematical literacy proficiency scale.

$43.5 \%$ (417 questions) of the questions in the book are at the second level of the PISA mathematical literacy proficiency scale. A student can make direct inferences and interpret those inferences on the second-level. They can extract necessary information 
Write the values of the following exponential expressions next to them.

\begin{tabular}{|l|l|l|l|l|}
\hline$-2^{4}=$ & $(-4)^{4}=$ & $(-6)^{2}=$ & $(-5)^{4}=$ & $(-4)^{2}=$ \\
\hline$(-7)^{2}=$ & $-11^{2}=$ & $(-5)^{2}=$ & $(-1)^{145}=$ & $(-1)^{1200}=$ \\
\hline
\end{tabular}

Figure 1. PISA mathematics literacy proficiency scale first level question example from MEB publications middle school 8th grade mathematics textbook (Page: 23, It's Your Turn, Question 1)

\section{Your Turn 4}

Find and write the exponents that are not given in the following equations.

\begin{tabular}{|l|l|l|l|}
\hline $300=2^{x} \cdot 3^{b} \cdot 5^{\mathrm{c}}$ & $\mathrm{a}=$ & $\mathrm{b}=$ & $\mathrm{c}=$ \\
\hline $700=2^{x} \cdot 5^{\mathrm{y}} \cdot 7^{\mathrm{x}}$ & $\mathrm{x}=$ & $\mathrm{y}=$ & $\mathrm{z}=$ \\
\hline $495=3^{m} \cdot 5^{n} \cdot 11^{\mathrm{k}}$ & $\mathrm{m}=$ & $\mathrm{n}=$ & $\mathrm{k}=$ \\
\hline
\end{tabular}

Figure 2. PISA mathematics literacy proficiency scale second level question example from MEB publications middle school 8th grade mathematics textbook (Page: 14, It's Your Turn, Question 4)

\section{Your Turn 4}

Answer the following questions.

a) When balls of equal size with numbers from 1 to 20 are put in a box, examine the probability that the number of a randomly selected ball is a prime number and that it is not a prime number. How many of which type must be removed from the bag so that the probability of a randomly selected ball's number being a prime number or a nonprime number is equal?

Figure 3. PISA mathematics literacy proficiency scale third level question example from MEB publications middle school 8th grade mathematics textbook (Page: 80, It's Your Turn, Question 4)

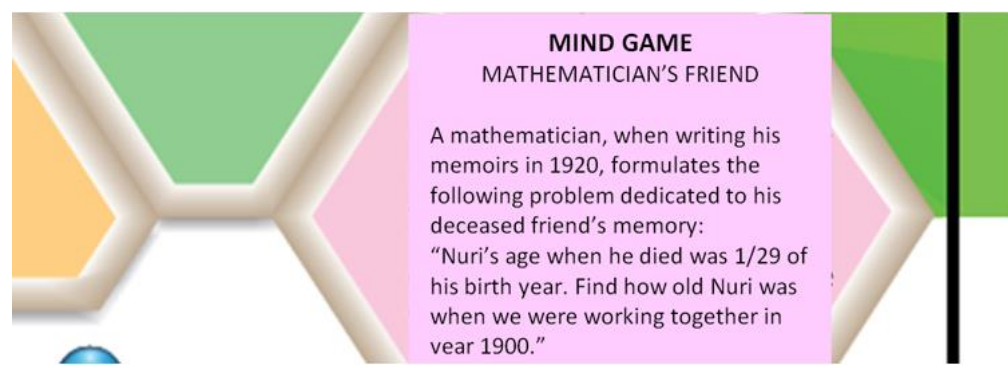

Figure 4. PISA mathematics literacy proficiency scale fourth level question example from MEB publications middle school 8th grade mathematics textbook (Page: 109, Mind Game)

from a single source. They can use representations. They can use rules and formulas. They can follow instructions. A second level question of the PISA mathematical literacy proficiency scale on page 14 of the book examined is given in Figure 2. Inspection of the question in Figure 2 shows that some steps need to be completed in order to solve the problem. First of all, the number should be factored and made into the product of the exponent of the prime factors, and then these exponents should be matched with the letters given in the equations. In this respect, the question is at the second level of the PISA mathematical literacy scale.

$35.6 \%$ of the questions in the book (341 questions) are at the third level of the PISA mathematical literacy proficiency scale. At the third-level, a student can follow directions that require sequential decisions. They can create a simple model. They can use simple problem solving strategies. They can use different sources of information. They can perform operations with percentages, fractions and decimals. They can understand proportional relationships. A third-level question of the PISA mathematical literacy proficiency scale on page 80 of the book examined is given in Figure 3. When the question in Figure $\mathbf{3}$ is examined, it is seen that an appropriate strategy should be determined to solve the problem and reasoning skills should be used to equalize the probabilities. For this, a number of sequential decisions must be made. In this respect, the question is a third-level question of the PISA mathematical literacy proficiency scale.

$1.3 \%$ of the questions in the book (12 questions) are at the fourth level according to the PISA mathematical literacy proficiency scale. Students at the fourth level can work effectively on models. They can engage in simple reasoning activities. They can select and combine different presentations. They can explain their interpretations and inferences. A question at the fourth level of the PISA mathematical literacy proficiency scale on page 109 of the book examined is given in Figure 4 . The question in Figure 4 requires that reasoning skills be used to solve the problem. First of all, it should be realized that the mathematician's friend died before 1920 and he was alive in 1900, that is, the date of his death was between these two years. After that, a series of operations and inferences must be made to reach the answer to the question. In this respect, this question is at the fourth level of the PISA mathematical literacy proficiency scale. 
Table 6. Distributions of the questions in the book by content, context, and mathematical process categories and levels of the PISA mathematics proficiency scale

\begin{tabular}{|c|c|c|c|c|c|c|c|}
\hline \multirow{2}{*}{ Category } & \multicolumn{7}{|c|}{ Proficiency level (N) } \\
\hline & 1st level & 2nd level & 3rd level & 4th level & 5th level & 6th level & Total \\
\hline \multicolumn{8}{|l|}{ Content category } \\
\hline Change and relationships & 15 & 67 & 40 & 0 & 0 & 0 & 122 \\
\hline Space and shape & 21 & 131 & 186 & 1 & 0 & 0 & 339 \\
\hline Quantity & 115 & 183 & 85 & 8 & 0 & 0 & 391 \\
\hline Uncertainty and data & 37 & 36 & 30 & 3 & 0 & 0 & 106 \\
\hline $\begin{array}{ll}\text { Total } \\
\end{array}$ & 188 & 417 & 341 & 12 & 0 & 0 & 958 \\
\hline \multicolumn{8}{|l|}{ Context category } \\
\hline Personal & 15 & 28 & 44 & 3 & 0 & 0 & 90 \\
\hline Occupational & 3 & 31 & 46 & 2 & 0 & 0 & 82 \\
\hline Societal & 1 & 6 & 7 & 0 & 0 & 0 & 14 \\
\hline Scientific & 169 & 352 & 244 & 7 & 0 & 0 & 772 \\
\hline $\begin{array}{r}\text { Total } \\
\end{array}$ & 188 & 417 & 341 & 12 & 0 & $\mathbf{0}$ & 958 \\
\hline \multicolumn{8}{|l|}{ Mathematical process category } \\
\hline Formulating situations mathematically & 3 & 18 & 7 & 0 & 0 & 0 & 28 \\
\hline $\begin{array}{l}\text { Employing mathematical concepts, facts, procedures, } \\
\text { \& reasoning }\end{array}$ & 169 & 368 & 229 & 1 & 0 & 0 & 767 \\
\hline $\begin{array}{l}\text { Interpretation, application, \& evaluation of } \\
\text { mathematical results }\end{array}$ & 16 & 31 & 105 & 11 & 0 & 0 & 163 \\
\hline $\begin{array}{l}\text { Total } \\
\end{array}$ & 188 & 417 & 341 & 12 & 0 & 0 & 958 \\
\hline
\end{tabular}

Table 7. Frequency and percentage distribution of questions by item types

\begin{tabular}{lcc}
\hline Item type & Frequency $(\mathbf{N})$ & Percentage (\%) \\
\hline Fill in the blanks & 58 & 6.1 \\
\hline Matching & 16 & 1.7 \\
\hline Sample-solution & 344 & 35.9 \\
\hline Multiple choice & 178 & 18.6 \\
\hline True-false & 11 & 1.1 \\
\hline Open-ended & 351 & 36.6 \\
\hline Total & $\mathbf{9 5 8}$ & $\mathbf{1 0 0 . 0}$ \\
\hline
\end{tabular}

The distributions of the questions in the book on the basis of content, context, and mathematical process categories and by the PISA mathematical literacy proficiency scale levels are given in Table 6 . As Table 6 shows, none of the content categories has a fifth and sixth level question according to the PISA mathematical literacy proficiency scale. Moreover, in the content category of "change and relationships" there was no fourth level question either. In general, all content categories except "space and shape" contain mostly first and second level questions. In the "space and shape" content area, there are mainly third-level questions. Inspection of the data in Table 6 reveals that there are no fifth and sixth level questions according to the PISA mathematical literacy proficiency scale in any of the contexts. At the same time, the fourth level question was not included in the "societal" context. In general, it is seen that there are mostly second and third level questions in all contexts. From Table 6 it is understood that there are no fifth and sixth level questions of the PISA mathematical literacy proficiency scale in any of the mathematical processes. At the same time, there was no question at the fourth level in the questions in which the mathematical process of "formulating situations mathematically" was involved. It is seen that high-level questions are generally introduced through the process of "interpretation, application and evaluation of mathematical results."

The distribution of the questions in the book by the item types is given in Table 7. Table 7 reveals that the majority of the questions in the book are presented in the open-ended question type with a maximum of $36.6 \%$ ( 351 questions). The total number of open-ended and sample-solution type questions is greater than half of all questions. The least preferred item type in asking questions in the book is true-false question type with $1.1 \%$ (11 questions).

The distribution of the questions in the book by the proficiency levels on the basis of item types is given in Table 8. Inspection of the data in Table 8 reveals that none of the item types have a fifth and sixth level question of the PISA mathematical literacy proficiency scale. Moreover, there are no fourth level questions in the "fill in the blanks", "matching", "true-false" item types. It is noted that the high-level questions are usually presented via the "open-ended" item type.

\section{DISCUSSION, CONCLUSION, AND RECOMMENDATIONS}

In this study, the questions in the Ministry of National Education Middle School Mathematics 8 Textbook, which is used as a mathematics textbook for 8th grades, were examined with regard to the mathematical literacy content categories, contexts, mathematical processes, Mathematics Proficiency Scale in PISA 2018 and question types. When the questions in the book were classified by their content category, $12.7 \%$ of the questions are in the change and relationships content category, $35.4 \%$ in the Space and shape content category, $40.8 \%$ in the quantity content category and $11.1 \%$ in the uncertainty and data content category. Distribution of mathematics items by content category in PISA exams are, as follows: change and relationships $25 \%$, 
Table 8. Distribution of the questions in the book by item types and the PISA mathematics proficiency scale levels

\begin{tabular}{|c|c|c|c|c|c|c|c|}
\hline \multirow{2}{*}{ Item type } & \multicolumn{7}{|c|}{ Proficiency level (N) } \\
\hline & 1st level & 2nd level & 3rd level & 4th level & 5th level & 6th level & Total \\
\hline Fill in the blanks & 34 & 21 & 3 & 0 & 0 & 0 & 58 \\
\hline Matching & 10 & 5 & 1 & 0 & 0 & 0 & 16 \\
\hline Sample-solution & 88 & 164 & 90 & 2 & 0 & 0 & 344 \\
\hline Multiple choice & 23 & 81 & 73 & 1 & 0 & 0 & 178 \\
\hline True-false & 4 & 5 & 2 & 0 & 0 & 0 & 11 \\
\hline Open-ended & 29 & 141 & 172 & 9 & 0 & 0 & 351 \\
\hline Total & 188 & 417 & 341 & 12 & 0 & 0 & 958 \\
\hline
\end{tabular}

space and shape $25 \%$, quantity $25 \%$, and uncertainty and data $25 \%$. In the OECD (2019a) report, it is stated that since all of these areas are important for individuals with constructive, productive and reflective thinking, it is important to have a balanced distribution. When the content distribution in the present book is examined, we can say that this balance is relatively skewed, especially considering that the amount of questions belonging to the "uncertainty and data" and "change and relationships" contents are lower. It can be suggested that these distributions be presented in a more balanced way in the books.

Context-based questions are important for students to associate and establish connections with real life. In the study conducted by Irwin (2001), one of two groups of eight students studied the subject of decimals with context-based questions, and the other group studied with questions without context. As a result of the study, the results of the pre-test and post-test were compared and it was seen that the students studying with the context-based questions on decimal numbers made more progress than the students studying on the decimal numbers with the questions without context. Distribution of questions according to context category in PISA exams is, as follows: personal context 25\%, professional context 25\%, societal context 25\%, and scientific context $25 \%$. It is seen that the distribution of the context-based questions in the book examined in the present study is $9.4 \%$ in the personal context, $8.6 \%$ in the professional context, $1.5 \%$ in the societal context, and $80.6 \%$ in the scientific context category. In PISA exams, a balanced distribution in terms of context is given importance and it is ensured that a single context type is not dominant alone. Thus, students are prepared for various problem situations they may encounter in their lives (OECD, 2019a). It is seen that the present book examined does not comply with this desired balanced distribution in terms of context category. It is concluded that it is important to distribute the questions in the book in a balanced way in various contexts.

When the questions in the current book are classified according to the mathematical process categories, $2.9 \%$ of these questions belong to the category of formulating situations mathematically, $80.1 \%$ of them to use mathematical concepts, facts, procedures and reasoning, and $17 \%$ to the category of interpretation, application and evaluation of mathematical results. The desired distribution of items according to the mathematical process in PISA exams is $25 \%$ formulating situations mathematically, $50 \%$ employing mathematical concepts, facts, procedures, and reasoning, and $25 \%$ interpretation, application, and evaluation of mathematical results (OECD, 2019a). It is noteworthy that there are very few questions in the category of mathematically formulating situations in the present book. In the process of formulating situations mathematically, the problem in the real life environment is transformed into the field of mathematics. These questions are especially questions that help students establish a connection between the mathematical world and the real world. Therefore, the presence of these questions in the books is very important. In this respect, a balanced distribution should be ensured.

In the present book, it is seen that the questions about mathematical concepts, facts, procedures and reasoning process are abundant. In parallel, Murdaningsih and Murtiyasa's (2016) study on the eighth grade mathematics textbook of the Indonesian curriculum also found that problems involving the process of employing mathematical concepts, facts, procedures, and reasoning were more prevalent than the others. In this process, individuals use necessary mathematical rules and properties to obtain results and find a mathematical result (solution). The large number of questions in this process category in the book shows that a more result-oriented approach to mathematics teaching is dominant. Considering that the questions in the high school entrance exam consist of multiple choice questions and generally focus on finding a numerical result, this finding can be considered normal. In other words, it is thought that the questions to be included in the book are determined by taking into account the existing national central exam questions while writing the books.

The mathematical performances of students in Turkey with regard to the mathematical processes in PISA 2012 are as follows; an average of 449 points from questions related to the process of formulating situations mathematically, and an average of 448 points from questions related to the process of Employing mathematical concepts, facts, procedures and reasoning, an average of 446 points from questions related to the process of Interpreting, applying and evaluating mathematical outcomes (OECD, 2014). Here, it is evident that the lowest achievement is obtained in the questions in the category of interpretation, application and evaluation of mathematical results (MEB, 2015). Based on these data, it is thought that increasing the number of questions related to this process in textbooks and creating a more balanced distribution will positively influence the PISA mathematics performance of students in Turkey.

When the questions in the present book are classified according to the PISA mathematical literacy proficiency scale, it is seen that majority of these questions are at the second proficiency level with $43.5 \%$. It is seen that the questions at the fourth level are very scarce in the book with 1.3\%, and the questions at the fifth and sixth level are not included in the book. This situation of the questions in the book is consistent with Turkey's PISA 2018 Turkey mathematics score average. PISA 2018 Turkey mathematics score average was determined as 454 points (OECD, 2019b). This score corresponds to the second level in the mathematics proficiency scale. One of the reasons for this level of success shown is that the students do not often encounter questions suitable for the high-levels on the proficiency scale. For this reason, it is seen as a necessity to have higher-level questions in the books. Tutak and Guder (2012) concluded in their study that the teachers generally know the textbook well, and they use the textbook as 
the main source in the lesson. Ozturk (2020) examined the questions in the central high school entrance exam in his study and determined that the level of questions in the exam was the second level with $45 \%$. Therefore, it can be concluded that the questions in the book were created by being influenced by the question levels in the central high school entrance exam.

When the questions in the present book are classified by item types, it is seen that the questions presented in the "openended" and "sample-solution" type are more preferred. It is seen that the least preferred item type is the "true-false" question type. When the distribution of the PISA mathematics proficiency scale high-level questions, which is rare in the book, by item types, is examined, it is noted that the most preferred item type in asking these questions is the "open-ended" item type. It is thought that the reason for this situation is that high-level skills, which are difficult to measure with other item types, can be easily measured with open-ended questions (Bilgec, 2016).

Considering the results obtained from this study, necessary adjustments can be made by adding high-level questions according to the PISA proficiency levels in the existing books. In the new books to be prepared, studies can be carried out to distribute the questions in a balanced way in terms of their contexts, contents and mathematical processes and to increase the number of high-level questions, so that desired books can be written in the context of mathematical literacy. The findings of this study can be used in revisions of the current mathematics curriculum. In this study, the questions in one of the 8th grade mathematics textbooks distributed to students by the Ministry of National Education were examined within the framework of PISA mathematical literacy. In future studies, mathematics textbooks of other grade levels can be examined. Considering the age group to which PISA is applied, especially the 9th grade textbooks can be examined within the framework of mathematical literacy.

Author contributions: All authors have sufficiently contributed to the study, and agreed with the results and conclusions.

Funding: No funding source is reported for this study.

Declaration of interest: No conflict of interest is declared by authors.

\section{REFERENCES}

Altun, M., Arslan, C., \& Yazgan, Y. (2004). A study on the use and frequency of high school mathematics textbooks. Uludag University Journal of Education Faculty, 17(2), 131-147.

Arslan, S., \& Ozpınar, I. (2009). Evaluation of 6th grade mathematics textbooks along with the teacher opinions. Journal of Dicle University Ziya Gokalp Faculty of Education, 12, 97-113.

Bilgec, I. (2016). Inspection of mathematic exams with open ended questions from the perspective of measurement and evaluation [Unpublished master's thesis]. Marmara University.

Bowen, G. A. (2009). Document analysis as a qualitative research method. Qualitative Research Journal, 9(2), 27-40. https://doi.org/10.3316/QRJ0902027

Cakir, I. (2009). The evaluation of the fifth grade mathematics textbooks of the primary education according to the views of the teachers and students [Unpublished master's thesis]. Cukurova University.

Canbazoglu, H. B. (2019). A practice of activity-based for improving mathematical literacy and awareness of pre-service elementary school teachers' [Master's thesis, Cukurova University].

Canbazoglu, H. B., \& Tarim, K. (2021). Elementary pre-service teachers' mathematical literacy problem posing skills and processes for developing a mathematical activity. Journal of National Education, 50(231), 147-172.

Canbazoglu, H. B., Tarım, K., \& Baypınar, K. (2019). Mathematical literacy. In G. Haciomeroglu, \& K. Tarim (Eds.), Fundamentals of mathematics education middle school (pp. 457-496). Anı Publishing.

Guder, Y., \& Tutak, T. (2012). The opinions of the primary 5th grade school teachers' views about mathematics textbook. Journal of Dicle University Ziya Gokalp Faculty of Education, 19, 16-28.

Irwin, K. C. (2001). Using everyday knowledge of decimals to enhance understanding. Journal for Research in Mathematics Education, 32(4), 399-420. https://doi.org/10.2307/749701

Iskenderoglu, T., \& Baki, A. (2011). Classification of the questions in an 8th grade mathematics textbook with respect to the competency levels of PISA. Education and Science, 36(161).

MEB. (2015). PISA 2012 survey national final report. General Directorate of Assessment, Evaluation and Examination Services, Ministry of National Education. https://pisa.meb.gov.tr/meb_iys_dosyalar/2020_12/23172540_pisa2012-ulusal-nihairaporu.pdf

MEB. (2019). PISA 2018 national preliminary report. Ministry of National Education. http://pisa.meb.gov.tr/wp-content/ uploads/2020/01/PISA_2018_Turkiye_On_Raporu.pdf

Murdaningsih, S., \& Murtiyasa, B. (2016). An analysis on eight grade mathematics textbook of new Indonesian curriculum (K-13) based on Pisa's framework. Journal of Research and Advances in Mathematics Education, 1(1), 14-27. https://doi.org/10.23917/jramathedu.v1i1.1780

OECD. (2014). Results: What students know and can do student performance in mathematics, reading and science. OECD Publishing.

OECD. (2019a). PISA 2018 assessment and analytical framework. OECD Publishing. https://doi.org/10.1787/b25efab8-en

OECD. (2019b). PISA 2018 results volume I: What students know and can do. OECD Publishing. 
Ozturk, N. (2020). Classification of the high school central exam math questions according to the Pisa mathematıcal literacy levels [Master's thesis, Sakarya University].

Seis, A. (2011). An investigation of 6th-8th grade mathematics textbooks according to PISA 2003 uncertainty scale [Master's thesis, Abant Izzet Baysal University].

Tyson, H., \& Woodward, A. (1989). Why students aren't learning very much from textbooks. Educational Leadership, 47(3), 14-17. Umay, A. (2003). Mathematıcal reasonıng ability. Hacettepe University Faculty of Education Journal, 2003(24), $234-243$.

Unsal, Y., \& Gunes, B. (2002). As an example of a textbook investigation critical view to physics-contents in primary school 4 th class science textbook prepared by Ministry of National Education. Gazi University Journal of Gazi Education Faculty, 22(3), $107-120$.

Yildirim, I. (2019). An investigation of 5-8th grade mathematics textbooks according to PISA change and relationships scale [Master's thesis, Bartin University]. 